\title{
Review Article \\ Chronic Periodontitis Case Definitions and Confounders in Periodontal Research: A Systematic Assessment
}

\author{
Zuhair S. Natto ${ }^{1 D},{ }^{1,2,3}$ Randa H. Abu Ahmad, ${ }^{1}$ Lina T. Alsharif, ${ }^{1}$ Hanan F. Alrowithi, \\ Duaa A. Alsini, ${ }^{1}$ Hetaf A. Salih, ${ }^{1}$ and Nabil F. Bissada ${ }^{4}$ \\ ${ }^{1}$ Department of Dental Public Health, School of Dentistry, King Abdulaziz University, Jeddah, Saudi Arabia \\ ${ }^{2}$ Department of Periodontology, School of Dental Medicine, Tufts University, Boston, MA, USA \\ ${ }^{3}$ Department of Oral Health Policy and Epidemiology, School of Dental Medicine, Harvard University, Boston, MA, USA \\ ${ }^{4}$ Department of Periodontics, School of Dental Medicine, Case Western Reserve University, Cleveland, OH, USA
}

Correspondence should be addressed to Zuhair S. Natto; znatto@kau.edu.sa

Received 29 June 2018; Revised 16 October 2018; Accepted 28 October 2018; Published 28 November 2018

Academic Editor: Koichiro Wada

Copyright (C) 2018 Zuhair S. Natto et al. This is an open access article distributed under the Creative Commons Attribution License, which permits unrestricted use, distribution, and reproduction in any medium, provided the original work is properly cited.

\begin{abstract}
Case definitions and criteria of periodontal diseases are not yet consistent worldwide. This can affect the accuracy of any comparison made between two studies. This study determines which are the most common chronic periodontitis case definitions as well as confounding variables that have been reported worldwide in periodontal literature. A systematic assessment on periodontal disease classification and confounders was conducted using all publications in MEDLINE, EMBASE, SCOPUS, and Google Scholar between 1965 and October 2017. Screening of eligible studies and data extraction were conducted in duplicate and independently by two reviewers. The search protocol produced 4,218 articles. Out of these, 492 potentially relevant articles were selected for review. Only 351 studies fulfilled the selection criteria. Combination of probing depth and clinical attachment loss was the most common chronic periodontitis case definitions used (121, studies, 34.5\%). CPI/CPITN was the most common classification used. Age was the most common confounder studied in periodontal research (303 studies, $86.3 \%$ ), followed by gender (268 studies, $76.4 \%$ ) and race (138 studies, 39.3\%). Albumin and creatinine were the least common variables studied (1 or 2 studies each). Different case definitions affect the prevalence and treatment consequences of periodontitis. We need to standardize periodontitis case definitions worldwide to avoid difficulties in case diagnosis and prognosis. Further studies need to be done to assess the association between periodontitis and several potential confounders.
\end{abstract}

\section{Introduction}

Periodontal disease and dental caries are the most common diseases in the oral cavity [1]. Chronic periodontitis is one of the periodontal diseases. It is a long-lasting inflammatory disease affecting the soft and hard tissues around the teeth [2] and it is common worldwide [3]. This disease is related to common and preventable biological risk factors (e.g., high blood pressure, high blood cholesterol, diabetes, genetic factors, and obesity) and behavioral risk factors (e.g., an unhealthy diet, physical inactivity, and tobacco use) [4]. Based on published studies, the severity and prevalence of the disease vary significantly among populations [1]. It could be due to several reasons such as differences in data collection methods or case definitions of periodontal diseases.
Chronic periodontitis is ideally diagnosed at the beginning of the disease. However, case definitions and criteria that are used to diagnose this disease are not yet consistent worldwide [5-13]. This can affect the accuracy of any comparison made between studies. Kassab et al. applied different definitions of periodontitis to assess the disease in postpartum women. They found that case definitions had different impacts on the frequency of periodontitis, and they produced various odds ratios for the associations with risk factors for periodontitis [13]. Manau et al. found that a different case definition can change the statistical significance and effect size between periodontitis and prematurity or low birth weight [14].

Moreover, several studies have shown there are various risk factors associated with chronic periodontitis $[1,3,15,16]$. 
However, recent factors have been investigated in published articles, and the number of associated confounders has increased dramatically since then. Furthermore, these reviews and articles have not described which variables are commonly investigated and which are not.

Thus, little is known about the common case definition of chronic periodontitis in epidemiological literature or the most common risk factors/predictors associated with such. So, the purpose of this systematic assessment was to assess the various definitions and factors of chronic periodontitis.

\section{Materials and Methods}

2.1. Search Strategies. We conducted a systematic literature review using all publications in MEDLINE, EMBASE, SCOPUS, and Google Scholar between 1965 and October 2017. The terms we used to identify epidemiological articles reporting on periodontist were the following: periodontal diseases (MeSH term and keyword), periodontal attachment loss (MeSH term and keyword), and periodontitis ( $\mathrm{MeSH}$ term and keyword). These terms were combined with one of the following terms: prevalence (MeSH term), epidemiologic studies (MeSH term), epidemiology (MeSH term), epidemiologic research design ( $\mathrm{MeSH}$ term), and risk $(\mathrm{MeSH}$ term). Hand-searched journals and bibliographies of the selected articles and reviews were checked for additional articles.

2.2. Eligibility Criteria. Included articles had to report the original article (i.e., letters to the editor and review studies were excluded); humans (i.e., animal and in vitro studies were excluded); and observational, population screening, or prevalence studies (i.e., case report, case series, and randomized clinical trial were excluded). The included chronic periodontitis definition and measurements were to be written in English only. We excluded articles describing gingivitis or other forms of periodontitis (e.g., aggressive and necrotizing ulcerative). Furthermore, we excluded any methodological and interventional studies as well as any studies for which the full text was not available/accessible through a license at our institutes.

2.3. Screening Process. Two reviewers (ZN) with either RA, LA, HA, DA, or HS independently screened and selected articles for eligibility based on title and abstract. Disagreements were resolved via discussion. After consensus, full-text articles were retrieved, and two reviewers $(\mathrm{ZN})$ with either RA, LA, HA, DA, or HS screened the full-text articles and extracted data. In case of doubt, a new third reviewer in the same group (RA, LA, HA, DA, or HS) was involved.

2.4. Data Extraction. Items extracted from articles included study design (e.g., cohort and case-control), type of disease, case definition, method of diagnosis, and predictors including but not limited to the following: age, gender, family history, race, smoking, body mass index (BMI), height, weight, physical activity, diet, psychosocial status, socioeconomic status, alcohol, diabetes, cardiovascular disease, blood
TABLE 1: Frequency and percentage of different chronic periodontitis case definitions.

\begin{tabular}{lc}
\hline Method & $\begin{array}{c}\text { Number of studies(\%) } \\
\mathrm{N}=351\end{array}$ \\
\hline Single criteria & \\
CAL & $54(15.4)$ \\
Radiograph & $19(5.4)$ \\
PD & $110(31.3)$ \\
ICD & $1(0.3)$ \\
\hline Combined criteria & \\
\hline PD+CAL & $121(34.5)$ \\
Radiograph + PD & $5(1.4)$ \\
CAL + furcation & $1(0.3)$ \\
CAL + radiograph & $4(1.1)$ \\
PD+CAL+BOP & $21(6.0)$ \\
PD+BOP & $7(2.0)$ \\
Edema +BOP +PD+ recession +mobility & $1(0.3)$ \\
PD+ CAL+ Radiograph & $4(1.1)$ \\
PD+ Furcation & $1(0.3)$ \\
PD+ Radiograph +BOP & $2(0.6)$ \\
\hline
\end{tabular}

CAL: clinical attachment level, PD: probing depth, and BOP: bleeding on probing.

pressure, other diseases, cholesterol, blood glucose, and Creactive protein.

To insure consistent data extraction, a standardized data extraction sheet was formed. It was tested and modified several times. All reviewers were trained on how to use the sheet and understand each component in it.

2.5. Descriptive Analysis. Results were summarized using descriptive statistics of frequencies and percentages. We did not perform a quantitative analysis, as this was beyond the scope of our review and meta-analysis for these definitions is inapplicable due to the heterogeneity and limited number of studies in several groups.

2.6. Patient Involvement. No patients were involved in any part of this study.

\section{Results}

The search strategy identified 4,218 unique articles, of which 3,726 were excluded based on title and abstract. In total, 492 full texts were screened, 451 of which met the eligibility criteria and were included in this review (Figure 1).

3.1. Case Definitions. Overall, 121 (34.5\%) articles used both probing depth (PD) and clinical attachment loss (CAL) combined, followed by PD only (110 studies, 31.3\%), CAL only (54 studies, $15.4 \%$ ), or radiograph only (19 studies, $5.4 \%$ ) (Table 1). There are several methods that have been used rarely, such as the combination of CAL with furcation and PD with furcation (one study each). The combination of PD 


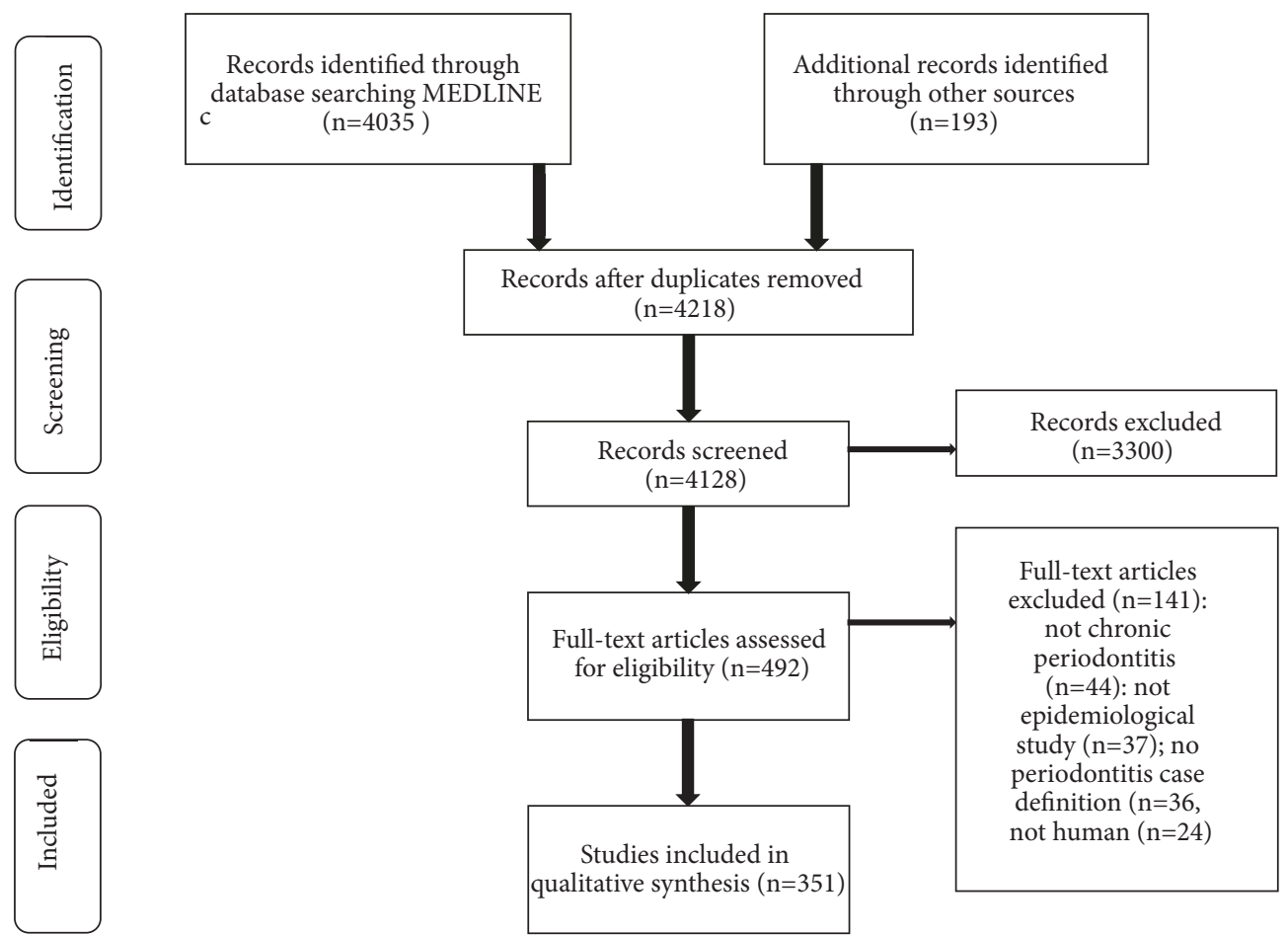

FIGURE 1: Flowchart of the systematic review.

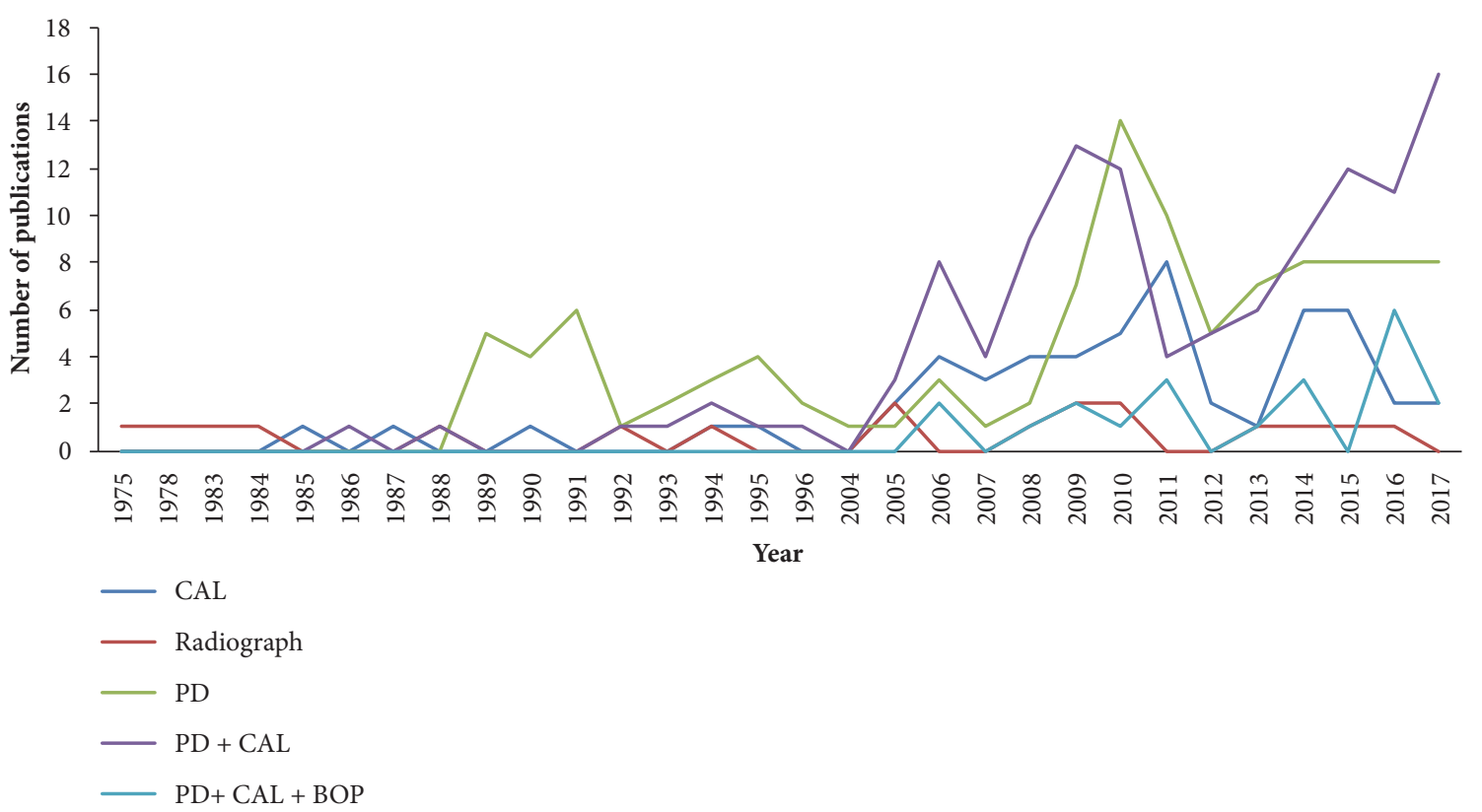

FIGURE 2: Numbers of articles based on the most common chronic periodontitis case definitions, ordered by publication year.

and CAL has been used more commonly in the recent 5 years, followed by PD (Figure 2).

Moreover, it is important to consider cases with $\mathrm{CAL} \geq 3$ periodontitis ( 21 studies, $6 \%$ ), followed by CAL $\geq 1$ ( 15 studies, $4.3 \%$ ) and $\mathrm{CAL} \geq 4$ (11 studies, 3.1\%) (Table 2). A minimum of two sites was the most common diagnostic criterion used. Bitewing was the most common method used in radiographic studies (11 studies, 3.1\%), followed by a minimum of $2 \mathrm{~mm}$ (4 studies, 1.1). While $\mathrm{PD} \geq 4$ was considered enough to diagnose with periodontitis (93 studies, 26.5\%), at least one site in this group was enough to diagnose with periodontitis (Table 2).

In the combination diagnostic criteria, $\mathrm{PD} \geq 4 \mathrm{~mm}$ and CAL $\geq 3 \mathrm{~mm}$ were the most common with 34 studies (9.7\%), followed by $\mathrm{PD} \geq 5 \mathrm{~mm}, \mathrm{CAL} \geq 4 \mathrm{~mm}$ (26 studies, 7.4\%), PD 
TABLE 2: Frequency and percentage of criteria and threshold used in chronic periodontitis case definitions.

\begin{tabular}{|c|c|c|c|}
\hline Definition & $\begin{array}{c}\text { Studies \# } \\
(\%) \\
\mathrm{N}=351 \\
\end{array}$ & Criteria & $\begin{array}{c}\text { Studies } \\
\#(\%) \\
N=224\end{array}$ \\
\hline \multicolumn{4}{|l|}{$\underline{C A L}$} \\
\hline $\mathrm{CAL} \geq 1$ & $15(4.3)$ & at least 2 sites & $6(2.7)$ \\
\hline $\mathrm{CAL} \geq 2$ & $2(0.6)$ & at least 3 sites & $4(1.8)$ \\
\hline $\mathrm{CAL} \geq 3$ & $21(6.0)$ & at least 4 sites & $3(1.3)$ \\
\hline $\mathrm{CAL} \geq 4$ & $11(3.1)$ & at least 1 site & $3(1.3)$ \\
\hline $\mathrm{CAL} \geq 5$ & $4(1.1)$ & at least $\geq 50 \%$ sites & $1(0.4)$ \\
\hline $\mathrm{CAL} \geq 6$ & $1(0.3)$ & $\mathrm{CAL} \geq 3$ in at least 2 sites and $\mathrm{CAL} \geq 5$ in $30 \%$ & $5(2.2)$ \\
\hline \multicolumn{4}{|l|}{ Radiograph } \\
\hline Bitewing + periapical & $2(0.6)$ & $\geq 2 \mathrm{~mm}$ & $4(1.8)$ \\
\hline Panorama & $6(1.7)$ & $\geq 3 \mathrm{~mm}$ & $2(0.9)$ \\
\hline Bitewing & $11(3.1)$ & $\geq 6 \mathrm{~mm}$ ( 2 studies at least one side) & $2(0.9)$ \\
\hline \multirow[t]{2}{*}{ Periapical } & $1(0.3)$ & $\geq 20 \%$ (one study at least 7 sites) & $3(1.3)$ \\
\hline & & $\geq 50 \%$ & $1(0.4)$ \\
\hline \multicolumn{4}{|l|}{$\underline{P D}$} \\
\hline $\mathrm{PD} \geq 4$ & $46(13.1)$ & at least 6 sites & $1(0.4)$ \\
\hline $\mathrm{PD} \geq 3.5$ & $47(13.4)$ & at least 10 sites & $2(0.9)$ \\
\hline $\mathrm{PD} \geq 3$ & $2(0.6)$ & at least 1 sites & $56(25.0)$ \\
\hline $\mathrm{PD} \geq 5$ & $12(3.4)$ & at least 3 sites (one study per quadrant) & $3(1.3)$ \\
\hline $\mathrm{PD} \geq 6$ & $2(0.6)$ & at least 1 tooth & $3(1.3)$ \\
\hline $\mathrm{PD} \geq 7$ & $1(0.3)$ & at least 4 sites & $2(0.9)$ \\
\hline \multicolumn{4}{|l|}{$\underline{P D+C A L}$} \\
\hline $\mathrm{PD} \geq 5 \mathrm{CAL} \geq 5$ & $3(0.9)$ & at least $10 \%$ sites $(\mathrm{PD}+\mathrm{CAL})$ & $1(0.4)$ \\
\hline $\mathrm{PD} \geq 5 \mathrm{CAL} \geq 4$ & $26(7.4)$ & 6 teeth with at least 1 site each & $1(0.4)$ \\
\hline $\mathrm{PD} \geq 5 \mathrm{CAL} \geq 3$ & $6(1.7)$ & at least 4 sites & $2(0.9)$ \\
\hline $\mathrm{PD} \geq 3 \mathrm{CAL} \geq 6$ & $1(0.3)$ & at least 2 sites CAL and 1 site PD & $36(16.1)$ \\
\hline $\mathrm{PD} \geq 3 \mathrm{CAL} \geq 1$ & $1(0.3)$ & at least 2 sites & $17(7.6)$ \\
\hline $\mathrm{PD} \geq 3 \mathrm{CAL} \geq 2$ & $1(0.3)$ & at least 2 teeth (one study with 3 sites PD and 3 studies with one site) & $7(3.1)$ \\
\hline $\mathrm{PD} \geq 3 \mathrm{CAL} \geq 3$ & $1(0.3)$ & at least 3 sites $\mathrm{PD}$ and 2 sites $\mathrm{CAL}$ & $2(0.9)$ \\
\hline $\mathrm{PD} \geq 3 \mathrm{CAL} \geq 4$ & $6(1.7)$ & at least 4 teeth and at least one site each & $9(4.0)$ \\
\hline $\mathrm{PD} \geq 4 \mathrm{CAL} \geq 3$ & $34(9.7)$ & at least 6 sites & $1(0.4)$ \\
\hline $\mathrm{PD} \geq 4 \mathrm{CAL} \geq 2$ & $5(1.4)$ & at least 6 teeth and at least one site each & $1(0.4)$ \\
\hline $\mathrm{PD} \geq 4 \mathrm{CAL} \geq 4$ & $14(4.0)$ & at least 8 teeth & $1(0.4)$ \\
\hline $\mathrm{PD} \geq 4 \mathrm{CAL} \geq 5$ & $4(1.1)$ & at least 4 sites (one study 4 sites CAL and one site PD & $2(0.9)$ \\
\hline $\mathrm{PD} \geq 5 \mathrm{CAL} \geq 6$ & $12(3.4)$ & at least one posterior tooth & $1(0.4)$ \\
\hline $\mathrm{PD} \geq 5 \mathrm{CAL} \geq 1$ & $1(0.3)$ & at least one site & $10(4.4)$ \\
\hline $\mathrm{PD} \geq 5 \mathrm{CAL} \geq 2$ & $1(0.3)$ & at least one tooth with at least one site & $1(0.4)$ \\
\hline $\mathrm{PD} \geq 6 \mathrm{CAL} \geq 4$ & $1(0.3)$ & at least two molars & $1(0.4)$ \\
\hline $\mathrm{PD} \geq 6 \mathrm{CAL} \geq 5$ & $3(0.9)$ & $\begin{array}{c}\text { CAL at more than one tooth site and with more than three sites of } \\
\text { probing depth }\end{array}$ & $1(0.4)$ \\
\hline \multirow[t]{2}{*}{$\mathrm{PD} \geq 6 \mathrm{CAL} \geq 6$} & $1(0.3)$ & CAL in at least two sites of different teeth and in at least one proximal site & $1(0.4)$ \\
\hline & & PD in one or more bleeding-positive sites and CAL in two or more sites. & $1(0.4)$ \\
\hline \multicolumn{4}{|l|}{$P D+$ Radiograph } \\
\hline $\mathrm{PD} \geq 4$ Radiograph bitewing & $1(0.3)$ & at least 10 pockets in 10 teeth & $1(0.4)$ \\
\hline $\mathrm{PD} \geq 5$ Radiograph panorama & $2(0.6)$ & & \\
\hline $\mathrm{PD} \geq 5$ Radiograph panorama & $2(0.6)$ & & \\
\hline \multicolumn{4}{|l|}{ CAL + furcation } \\
\hline $\mathrm{CAL} \geq 1 \&$ furcation & $1(0.3)$ & & \\
\hline
\end{tabular}


TABLE 2: Continued.

\begin{tabular}{|c|c|c|c|}
\hline Definition & $\begin{array}{c}\text { Studies \# } \\
(\%) \\
\mathrm{N}=351\end{array}$ & Criteria & $\begin{array}{c}\text { Studies } \\
\#(\%) \\
\mathrm{N}=224\end{array}$ \\
\hline \multicolumn{4}{|l|}{$C A L+$ radiograph } \\
\hline CAL $\geq 1$ \&Radiograph bitewing & $1(0.3)$ & $\begin{array}{c}\text { CAL } 30 \% \text { or more of the sites, and } 20>\% \text { bone loss as estimated from the } \\
\text { radiographs }\end{array}$ & $1(0.4)$ \\
\hline CAL $\geq 2$ \&Radiograph bitewing & $1(0.3)$ & & \\
\hline $\mathrm{CAL} \geq 4$ \&Radiograph bitewing & $2(0.6)$ & & \\
\hline \multicolumn{4}{|l|}{$\underline{P D+C A L+B O P}$} \\
\hline$\overline{\mathrm{PD}} \geq 5 \mathrm{CAL} \geq 5 \mathrm{BOP}$ & $5(1.4)$ & $\begin{array}{l}10 \% \text { of teeth with PD or CAL } \geq 5 \mathrm{mmm} \text { or } 15 \% \text { of teeth with PD or CAL } \\
\qquad 4 \mathrm{~mm} \text { and } 10 \% \text { of sites with BOP }\end{array}$ & $1(0.4)$ \\
\hline $\mathrm{PD} \geq 4 \mathrm{CAL} \geq 3 \mathrm{BOP}$ & $8(2.3)$ & at least 2 teeth and one tooth $\mathrm{BOP}$ & $1(0.4)$ \\
\hline $\mathrm{PD} \geq 4 \mathrm{CAL} \geq 2 \mathrm{BOP}$ & $2(0.6)$ & at least 4 teeth with one or more site & $11(4.9)$ \\
\hline $\mathrm{PD} \geq 4 \mathrm{CAL} \geq 4 \mathrm{BOP}$ & $1(0.3)$ & at least 5 sites & $2(0.9)$ \\
\hline $\mathrm{PD} \geq 5 \mathrm{CAL} \geq 3 \mathrm{BOP}$ & $4(1.1)$ & at least 8 sites & $1(0.4)$ \\
\hline $\mathrm{PD} \geq 6 \mathrm{CAL} \geq 3 \mathrm{BOP}$ & $1(0.3)$ & at least one site & $1(0.4)$ \\
\hline \multicolumn{4}{|l|}{$\underline{P D+B O P}$} \\
\hline $\mathrm{PD} \geq 3 \mathrm{BOP}$ & $4(1.1)$ & at least four teeth & $2(0.9)$ \\
\hline $\mathrm{PD} \geq 4 \mathrm{BOP}$ & $2(0.6)$ & & \\
\hline $\mathrm{PD} \geq 5 \mathrm{BOP}$ & $1(0.3)$ & & \\
\hline \multicolumn{4}{|l|}{$P D+C A L+$ Radiograph } \\
\hline$\overline{\mathrm{PD}} \geq 5$ CAL $\geq 6$ \& Radiograph & $1(0.3)$ & at least 2 sites & $1(0.4)$ \\
\hline $\mathrm{PD} \geq 4 \mathrm{CAL} \geq 4 \&$ Radiograph & $2(0.6)$ & at least 3 sites in at least 3 quadrant & $2(0.9)$ \\
\hline $\mathrm{PD} \geq 5 \mathrm{CAL} \geq 5$ \& Radiograph & $1(0.3)$ & & \\
\hline \multicolumn{4}{|l|}{ Edema $+B O P+P D+$ recession + mobility } \\
\hline$\overline{\text { edema }+\mathrm{BOP}+\mathrm{PD}+\text { recession }+ \text { mobility }}$ & $1(0.3)$ & If two or more parameters & $1(0.4)$ \\
\hline \multicolumn{4}{|l|}{$\underline{P D+\text { furcation }}$} \\
\hline$\overline{\mathrm{PD} \& \text { furcation }}$ & $1(0.3)$ & at least 8 teeth & $1(0.4)$ \\
\hline \multicolumn{4}{|l|}{$P D+$ Radiograph $+B O P$} \\
\hline $\mathrm{PD} \geq 4$ \& Radiograph & $1(0.3)$ & $10 \%$ of teeth with radiograph at least one tooth PD $15 \%$ BOP & $1(0.4)$ \\
\hline $\mathrm{PD} \geq 5$ \& Radiograph & $1(0.3)$ & & \\
\hline
\end{tabular}

CAL: clinical attachment level, PD: probing depth, and BOP: bleeding on probing.

$\geq 4 \mathrm{~mm}$ with CAL $\geq 4 \mathrm{~mm}$ (14 studies, $4.0 \%$ ), and PD $\geq 5 \mathrm{~mm}$ with CAL $\geq 6 \mathrm{~mm}$ (12 studies, 3.4\%) (Table 2). At least 2 sites CAL and one site PD and at least 2 sites each were the most common in the category (36 studies, $16.1 \%$, and 17 studies, $7.6 \%$, respectively) (Table 2 ).

The results did not change with three criteria (e.g., $\mathrm{PD}$, $\mathrm{CAL}$, and $\mathrm{BOP}$ ). $\mathrm{PD} \geq 4 \mathrm{~mm}$ with $\mathrm{CAL} \geq 3 \mathrm{~mm}$ and $\mathrm{BOP}$ was the most common ( 8 studies, $2.3 \%$ ). At least four teeth with one or more site had 11 studies $(4.9 \%)$ (Table 2 ).

3.2. Severity. There is no clear distinction between the three types of periodontitis (Table 3). However, it is more common to use Center for Disease Control/American Academy of Periodontology (CDC/AAP) working group classification, published by Eke et al. (42 studies), which divides cases as $\mathrm{PD} \geq 5$ and $\mathrm{CAL} \geq 4$ for moderate, $\mathrm{PD} \geq 5$ and $\mathrm{CAL} \geq 6$ for severe chronic periodontitis, and Armitage classification (15 studies), which divided CAL into 1-2 mm (mild), 3-4 mm (moderate), and CAL $\geq 5 \mathrm{~mm}$ (severe).
3.3. Predictors/Confounders. The median number of predictors included in articles was 3 (range 1-17). Age and gender were included in 303 articles (86.3\%) and 268 articles (76.4\%), respectively (Figure 3 ). Other prevalently selected predictors were race $(138,39.3 \%)$, smoking $(135,38.5 \%)$, diabetes $(75$, $21.4 \%)$, other diseases (71, 20.2\%), and BMI (62, 17.7\%). However, certain variables were included in few articles such as family history of periodontitis $(11,3.1 \%)$, genetics $(11,3.1 \%)$, C-reactive protein $(9,2.6 \%)$, creatinine $(5,1.4 \%)$, and albumin $(2,0.6 \%)$.

\section{Discussion}

The case definition for a disease is the key factor for any specialty. It is different from diagnosis because case definitions must be more quantitative, specific, accurately measurable, and relatively few in number [7]. This is an important issue in the periodontal research field [6-8, 10, 17-21]. We have shown in this article that there are different definitions 


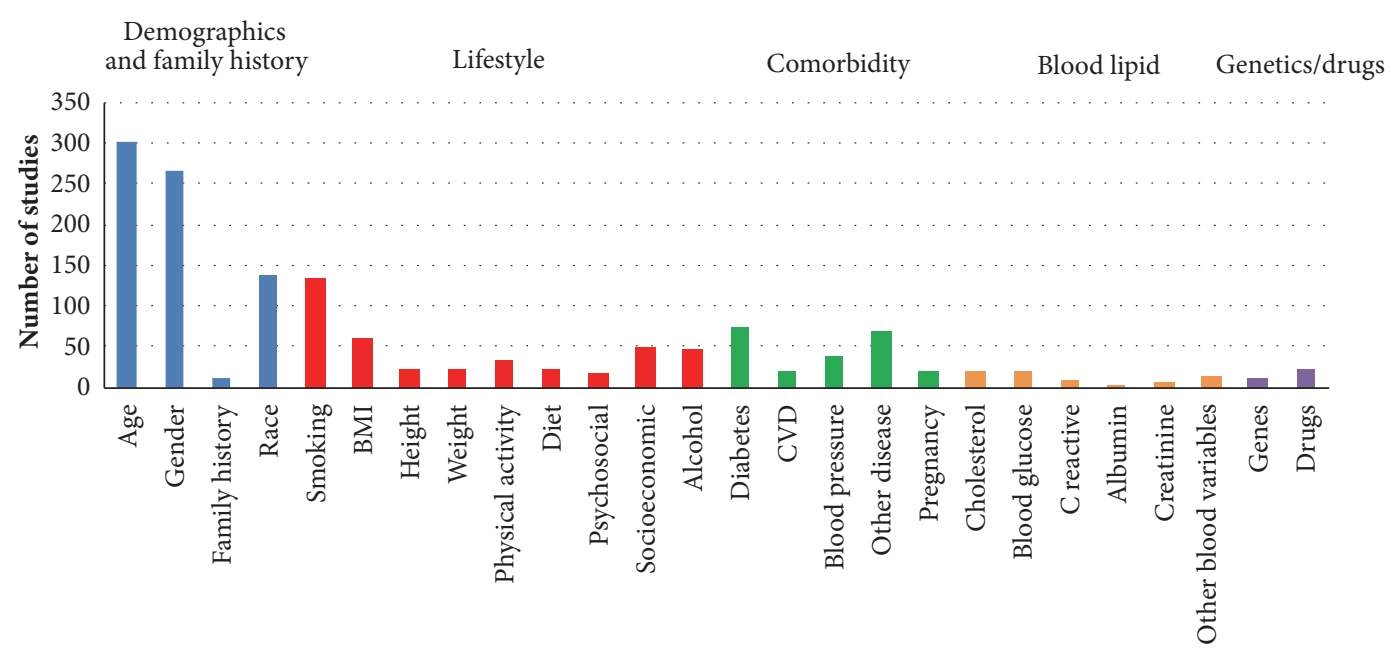

Figure 3: Predictors included in selected articles.

for chronic periodontitis in the literature, which can affect estimates of prevalence, incidence, and treatment strategies. It is also clear that variation in threshold values-for CAL, $\mathrm{PD}$, radiograph, or any combination at a given site-leads to different diagnosis of chronic periodontitis at that site. In addition, the number of involved sites $[7,12,22]$. Selection of threshold values is very critical and has been stated in several articles [7, 12, 22]. Any changes in these values or number of sites can lead to major changes in the prevalence scores, which may overestimate or underestimate the actual disease status.

Type and number of methods used is another factor which can affect the prevalence. Although each method has it is advantage such as probing depth assess the depth of the periodontal pocket and may represent current disease status [23], CAL and radiograph measure lifetime accumulated past disease $[8,10,17]$, bleeding on probing (BOP) indicates the presence of active signs of inflammation $[7,23]$, there is no consensus regarding the best method used. In the current article, some studies used one method, and other studies combined two or more methods to have more accurate decision.

Many studies have been conducted using different diagnostic classifications regarding periodontitis. The most common classification that used a single criterion was CPI/CPITN (Community Periodontal Index/Community Periodontal Index of Treatment Needs) of which they used $\mathrm{PD} \geq 3.5 \mathrm{~mm}$ as a cut point $(13.4 \%)$. This classification consumes less time because they only record the upper and lower first molars, the upper right central incisor, and the lower left central incisor [24, 25]. This makes it fast and easy to apply in large samples of people $[24,25]$. International uniformity is the most important advantage, but it does not record irreversible changes such as recession or loss of periodontal attachment [26].

Moreover, the 1999 AAP classification (Armitage classification) was not common in these articles. This is not a surprise because it is useful for clinicians [7] and has a little value in establishing case definitions for use in the surveillance of periodontitis worldwide [7].

The most common definition which used two criteria was the CDC/AAP working group, published in 2007, for moderate and severe [7]. They used CAL $\geq 4 \mathrm{~mm}$ and PD $\geq$ $5 \mathrm{~mm}$ in at least 2 interproximal sites (not on the same tooth) for moderate chronic periodontitis and $\mathrm{CAL} \geq 6 \mathrm{~mm}$ in at least 2 interproximal sites (not on the same tooth) and PD $\geq 5 \mathrm{~mm}$ in at least one site for severe chronic periodontitis. Then, they proposed a definition for mild periodontitis in 2012 which was CAL $\geq 3 \mathrm{~mm}$ and PD $\geq 4 \mathrm{~mm}$ in at least 2 interproximal sites (not on the same tooth) or one site with $\mathrm{PD} \geq 5 \mathrm{~mm}[6]$.

The recent 2017 World Workshop on the Classification of Periodontal and Peri-Implant Diseases and Conditions, copresented by the American Academy of Periodontology (AAP) and the European Federation of Periodontology (EFP) $[27,28]$, introduced new parameters based on certain articles. However, it is too early to assess the actual effect of this consensus and its acceptance globally.

After results analysis of all variables included in these articles, we found the most present predicators/risk factors associated with chronic periodontitis in periodontal literature were age, gender, and race. In age, as one becomes older, the risk of chronic diseases will increase. The physiological outcome of the ageing process (free radicals), which is the main factor associated with tissue destruction, will result in chronic inflammation [4, 29].

Gender is the second most common variable investigated. Different studies showed that males are more prone to periodontal disease than females, with the assumption of bad oral hygiene and less professional care as the reason for calculus decomposition [30,31]. There are no enough studies which represent the relationship between race (the third most common variable) and periodontitis.

Cigarette smoking is an important risk factor in the development of inflammatory periodontal diseases [3234]. It causes harmful effects on gingival tissues, immune 
TABLE 3: Frequency and percentage of chronic periodontitis severity case definitions.

\begin{tabular}{|c|c|}
\hline Definition of severity & $\begin{array}{c}\text { Studies \# } \\
(\%)\end{array}$ \\
\hline \multicolumn{2}{|l|}{ Severe } \\
\hline \multicolumn{2}{|l|}{ CAL: } \\
\hline at least 1 site $\mathrm{CAL} \geq 6$ & $2(2.1)$ \\
\hline at least 2 teeth $C A L \geq 6 \mathrm{~mm}$ & $1(1.1)$ \\
\hline at least 2 sites $\mathrm{CAL} \geq 4$ & $1(1.1)$ \\
\hline at least $30 \%$ sites $\mathrm{CAL} \geq 5$ & $3(3.2)$ \\
\hline $\mathrm{CAL} \geq 6 \mathrm{~mm}$ & $2(2.1)$ \\
\hline $\mathrm{CAL} \geq 5 \mathrm{~mm}$ & $15(16.0)$ \\
\hline \multicolumn{2}{|l|}{ Radiograph: } \\
\hline$>50 \%$ of the root & $4(4.3)$ \\
\hline $\begin{array}{l}>33 \% \text { of the roots, or if angular bony } \\
\text { defects/furcation defects degree II and III in more } \\
\text { than } 3 \text { teeth (molar and premolar regions) }\end{array}$ & $1(1.1)$ \\
\hline \multicolumn{2}{|l|}{ PD: } \\
\hline $\mathrm{PD} \geq 6 \mathrm{~mm}$ & $4(4.3)$ \\
\hline $\mathrm{PD}$ of $\geq 4 \mathrm{~mm}$ and at least 10 sites of $\mathrm{PD} \geq 6 \mathrm{~mm}$. & $1(1.1)$ \\
\hline$\geq 19$ sites $\mathrm{PD} \geq 5 \mathrm{~mm}$ & $1(1.1)$ \\
\hline PD 7 to $8 \mathrm{~mm}$ & $1(1.1)$ \\
\hline $\mathrm{PD}>7.5 \mathrm{~mm}$ & $1(1.1)$ \\
\hline $\mathrm{PD} \geq 4$ & $1(1.1)$ \\
\hline $\begin{array}{l}\text { at least } 10 \% \text { of sites with } \mathrm{PD} \geq 6 \mathrm{~mm} \text { (moderate to } \\
\text { severe ) }\end{array}$ & $1(1.1)$ \\
\hline \multicolumn{2}{|l|}{ PD + CAL: } \\
\hline $\mathrm{PD}$ and $\mathrm{CAL} \geq 5 \mathrm{~mm}$ & $1(1.1)$ \\
\hline $\mathrm{PD} \geq 4$ and $\mathrm{CAL} \geq 6$ & $1(1.1)$ \\
\hline $\mathrm{PD} \geq 5$ and $\mathrm{CAL} \geq 6$ & $2(2.1)$ \\
\hline $\mathrm{PD} \geq 5$ and $\mathrm{CAL} \geq 4$ (moderate or severe) & $42(44.7)$ \\
\hline $\begin{array}{l}\text { at least two sites } C A L \geq 6 \mathrm{~mm} \text { (not on same tooth) } \\
\text { and at least one site with } P D \geq 5 \mathrm{~mm}\end{array}$ & $1(1.1)$ \\
\hline $\mathrm{PD} \geq 6$ and $\mathrm{CAL} \geq 5$ & $1(1.1)$ \\
\hline $\mathrm{PD}$ and $\mathrm{CAL} \geq 5 \mathrm{~mm}$ & $2(2.1)$ \\
\hline $\mathrm{PD}$ and $\mathrm{CAL} \geq 6 \mathrm{~mm}$ & $1(1.1)$ \\
\hline \multicolumn{2}{|l|}{ CAL or PD with radiograph: } \\
\hline $\mathrm{PD} \geq 5$ and radiographic panorama $\geq 30$ & $1(1.1)$ \\
\hline $\begin{array}{l}\text { CAL }>6 \mathrm{~mm} \text {, grade II and/or III furcation, possible } \\
\text { tooth mobility class II or III }\end{array}$ & $1(1.1)$ \\
\hline \multicolumn{2}{|l|}{ PD + CAL+ BOP: } \\
\hline $\mathrm{PD} \geq 5, \mathrm{CAL} \geq 6$ and $\mathrm{BOP}$ & $1(1.1)$ \\
\hline $\mathrm{PD} \geq 5, \mathrm{CAL} \geq 6 \mathrm{BOP} \geq 30$ & $1(1.1)$ \\
\hline Total & $94(100)$ \\
\hline \multicolumn{2}{|l|}{ Moderate } \\
\hline \multicolumn{2}{|l|}{ CAL: } \\
\hline CAL 3-4 mm & $15(42.9)$ \\
\hline CAL 3 to $6 \mathrm{~mm} \mathrm{CAL}$ & $1(2.9)$ \\
\hline 3 sites with CAL $\geq 4 \mathrm{~mm}$ & $1(2.9)$ \\
\hline
\end{tabular}

TABle 3: Continued.

\begin{tabular}{lc}
\hline Definition of severity & $\begin{array}{c}\text { Studies \# } \\
(\%)\end{array}$ \\
\hline Radiograph: &
\end{tabular}

$20-30 \%$ of the root

$>2 \mathrm{~mm}$ not exceeding one-third of the roots, or if angular bony defects/furcation defects degree II and III in 2-3 teeth (molar and premolar regions)

PD:

PD 4-5 mm

PD with $\geq 4 \mathrm{~mm}$ and a maximum of 9 sites with PPD of $\geq 6 \mathrm{~mm}$

$\geq 7$ to 18 sites $\mathrm{PD} \geq 5 \mathrm{~mm}$

$\mathrm{PD} \geq 3$

PD 5.5 and $7.5 \mathrm{~mm}$

PD 5 to $8 \mathrm{~mm}$

PD + CAL:

$\mathrm{PD} \geq 4$ and $\mathrm{CAL} \geq 4$

$\mathrm{PD} \geq 5$ and $\mathrm{CAL} \geq 4$

$\mathrm{PD}>5 \mathrm{~mm}$ and $\mathrm{CAL}=3-4 \mathrm{~mm}$

$\mathrm{PD}$ and $\mathrm{CAL} \geq 3$ and $<5 \mathrm{~mm}$

$\mathrm{PD} \geq 4$ and $\mathrm{CAL} \geq 4 \mathrm{~mm}$

at least one site with both $\geq 4 \mathrm{~mm}$ and PD of $\geq 4 \mathrm{~mm}$

CAL or PD with radiograph:

CAL 4-6 mm, grade I and/or II furcation, and possible tooth mobility class I

$\mathrm{PD}+\mathrm{CAL}+\mathrm{BOP}$

$\mathrm{PD} \geq 5, \mathrm{CAL} \geq 4$ and $\mathrm{BOP}$

$\mathrm{PD} \geq 5, \mathrm{CAL} \geq 3$ and $\mathrm{BOP} \geq 30$

Total

$\underline{\text { Mild }}$

CAL:

CAL 4-5 mm

at least 2 teeth $\mathrm{CAL} \geq 1 \mathrm{~mm}$

at least at one site $\mathrm{CAL}<3 \mathrm{~mm}$

CAL of 1-2 mm

$15(60.0)$

PD:

mild or no disease with PPD of $\leq 4 \mathrm{~mm}$

$\geq 3$ to 6 sites that are $P D \geq 5 \mathrm{~mm}$

PD 4 to $5 \mathrm{~mm}$

PD 3.5 and $5.5 \mathrm{~mm}$

PD + CAL

$\mathrm{PD}>5 \mathrm{~mm}$ and $\mathrm{CAL}=1-2$

CAL or PD with radiograph

$\mathrm{CAL} \leq 4 \mathrm{~mm}$ and possible class I furcation invasion areas

Total

CAL: clinical attachment level, PD: probing depth, and BOP: bleeding on probing. 
responses, and the healing potential of the oral cavity [32, 35, 36]. Diabetes is another commonly investigated factor. Grossi (1994) reported a strong association with diabetes and attachment loss, with an odds ratio of 2.32 (95\% CI: 1.17-4.60) [37, 38]. Emrich (1991) investigated type 2 diabetes subjects within the Pima Indian population. They had an increased risk of periodontitis (OR: 2.81, 95\% CI: 1.91-4.13), and when bone loss was used to measure periodontal destruction, there was an odds ratio of 3.43 (95\% CI: 2.28-5.16) [39].

The least present variables were albumin and creatinine level which may need further investigation in the future. A study by Shimazaki et al. (2013) suggests that there is an inverse relationship between creatinine level and chronic periodontitis. Although some of the biomarkers can be improved by chronic periodontitis treatment, creatinine level depends on renal function [40, 41]. Several studies concluded that there is an inverse relationship between albumin level and periodontitis. Serum albumin level is affected by inflammation and malnutrition; however, other studies found that it difficult to estimate. Although there is a correlation, the relationship between them could not be established [40, 41].

Several clinical examination methods, threshold values, and criteria of chronic periodontitis were used in this research, including measurement of probing depth (PD), clinical attachment loss (CAL), bleeding on probing (BOP), and alveolar bone loss with or without radiographs. Different studies proposed different chronic periodontitis definitions; some used a combination of methods, and some used a single method. Thus, there is a lack of standardization, which leads to difficulty in drawing valid conclusions and serious impairment in accepting the results. Clear definitions of the disease and associated threshold values and criteria should be established worldwide to ensure accurate results in future studies. The most common predictors/confounders associated with the chronic periodontitis were age and gender. However, other variables need more investigation to assess their association with the disease.

\section{Additional Points}

Scientific Rationale for the Study. Case definitions and criteria of periodontal diseases are not yet consistent worldwide. This can affect the accuracy of any comparison made between two studies. Moreover, several articles have shown that there are various factors associated with periodontitis. Thus, little is known about the common case definitions and confounders of chronic periodontitis in epidemiological literature. Principal Findings. The included studies used different periodontitis definitions and criteria. Some used combinations parameters, and some used a single parameter, which led to difficulty in drawing valid conclusions as well as serious impairment in accepting the results. Practical Implications. A clear definition of the disease and associated parameters should be established worldwide for solid results in future studies. In addition, several variables need more investigation to assess their association with the disease.

\section{Conflicts of Interest}

The authors have stated explicitly that there are no conflicts of interest in connection with this article

\section{Acknowledgments}

The authors acknowledge Nouf Almeganni, Dr. Elaf Alnakeeb, Dr. Zuhor Bukhari, and Dr. Roaa Jan for their assistance with articles search.

\section{Supplementary Materials}

S1 Text: list of included articles categorized based on each criterion used in chronic periodontitis case definitions: CAL: clinical attachment level, PD: Probing depth, and BOP: bleeding on probing. (Supplementary Materials)

\section{References}

[1] J. M. Albandar, "Epidemiology and risk factors of periodontal diseases," Dental Clinics of North America, vol. 49, no. 3, pp. 517532, 2005.

[2] A. C. Bueno, R. C. Ferreira, L. O. M. Cota, G. C. Silva, C. S. Magalhães, and A. N. Moreira, "Comparison of different criteria for periodontitis case definition in head and neck cancer individuals," Supportive Care in Cancer, vol. 23, no. 9, pp. 25992604, 2015.

[3] J. M. Albandar and T. E. Rams, "Global epidemiology of periodontal diseases: An overview," Periodontology 2000, vol. 29, no. 1, pp. 7-10, 2002.

[4] M. A. Reynolds, "Modifiable risk factors in periodontitis: At the intersection of aging and disease," Periodontology 2000, vol. 64, no. 1, pp. 7-19, 2014.

[5] P. S. Anand and K. P. Kamath, "Letter to the editor: Re: Update of the case definitions for population-based surveillance of periodontitis," Journal of Periodontology, vol. 85, no. 6, pp. 765766, 2014.

[6] P. I. Eke, R. C. Page, L. Wei, G. Thornton-Evans, and R. J. Genco, "Update of the case definitions for population-based surveillance of periodontitis," Journal of Periodontology, vol. 83, no. 12, pp. 1449-1454, 2012.

[7] R. C. Page and P. I. Eke, "Case definitions for use in populationbased surveillance of periodontitis," Journal of Periodontology, vol. 78, no. 7, pp. 1387-1399, 2007.

[8] A. Savage, K. A. Eaton, D. R. Moles, and I. Needleman, "A systematic review of definitions of periodontitis and methods that have been used to identify this disease," Journal of Clinical Periodontology, vol. 36, no. 6, pp. 458-467, 2009.

[9] J. A. Martin, A. C. Grill, A. G. Matthews et al., "Periodontal Diagnosis Affected by Variation in Terminology," Journal of Periodontology, vol. 84, no. 5, pp. 606-613, 2013.

[10] M. S. Tonetti and N. Claffey, "Advances in the progression of periodontitis and proposal of definitions of a periodontitis case and disease progression for use in risk factor research: Group C Consensus report of the 5th European workshop in periodontology," Journal of Clinical Periodontology, vol. 32, no. 6, pp. 210-213, 2005.

[11] G. R. Persson, "Site-based versus subject-based periodontal diagnosis," Periodontology 2000, vol. 39, pp. 145-163, 2005. 
[12] F. O. Costa, A. N. Guimarães, L. O. M. Cota et al., "Impact of different periodontitis case definitions on periodontal research," Journal of oral science, vol. 51, no. 2, pp. 199-206, 2009.

[13] P. Kassab, M.-L. Colombier, M. Kaminski, N. Lelong, M. Sixou, and C. Nabet, "Impact of periodontitis definition in epidemiological research. Results from the EPIPAP study in postpartum women," European Journal of Oral Sciences, vol. 119, no. 2, pp. 156-162, 2011.

[14] C. Manau, A. Echeverria, A. Agueda, A. Guerrero, and J. J. Echeverria, "Periodontal disease definition may determine the association between periodontitis and pregnancy outcomes," Journal of Clinical Periodontology, vol. 35, no. 5, pp. 385-397, 2008.

[15] M. Bhat, K. Roberts-Thomson, and L. G. Do, "Clustering of risk indicators for periodontal disease: A population-based study," Community Dental Health, vol. 32, no. 3, pp. 158-62, 2015.

[16] U. M. Irfan, D. V. Dawson, and N. F. Bissada, "Epidemiology of periodontal disease: a review and clinical perspectives," Journal of the International Academy of Periodontology, vol. 3, no. 1, pp. 14-21, 2001.

[17] L. N. Borrell and P. N. Papapanou, "Analytical epidemiology of periodontitis," Journal of Clinical Periodontology, vol. 32, no. 6, pp. 132-158, 2005.

[18] R. Leroy, K. A. Eaton, and A. Savage, "Methodological issues in epidemiological studies of periodontitis - how can it be improved?" BMC Oral Health, vol. 10, no. 1, 2010.

[19] R. Lopez and V. Baelum, "Classifying periodontitis among adolescents: Implications for epidemiological research," Community Dentistry and Oral Epidemiology, vol. 31, no. 2, pp. 136143, 2003.

[20] P. Meisel and T. Kocher, "Definitions of periodontal disease in research: An alternative view," Journal of Clinical Periodontology, vol. 36, no. 5, pp. 411-412, 2009.

[21] P. M. Preshaw, "Definitions of periodontal disease in research," Journal of Clinical Periodontology, vol. 36, no. 1, pp. 1-2, 2009.

[22] B. Burt, "Position paper: epidemiology of periodontal diseases," Journal of Periodontology, vol. 76, no. 8, pp. 1406-1419, 2005.

[23] G. C. Armitage, "Diagnosis of periodontal diseases," Journal of Periodontology, vol. 74, no. 8, pp. 1237-1247, 2003.

[24] J. Ainamo, D. Barmes, G. Beagrie, T. Cutress, J. Martin, and J. Sardo-Infirri, "Development of the World Health Organization (WHO) community periodontal index of treatment needs (CPITN)," International Dental Journal, vol. 32, no. 3, pp. 281291, 1982.

[25] M. A. Listgarten, C. C. Schifter, and L. Laster, "3-year longitudinal study of the periodontal status of an adult population with gingivitis," Journal of Clinical Periodontology, vol. 12, no. 3, pp. 225-238, 1985.

[26] R. C. Page and E. C. Morrison, "Summary of outcomes and recommendations of the workshop on (CPITN)," International Dental Journal, vol. 44, no. 5 Suppl 1, pp. 589-594, 1994.

[27] J. G. Caton, G. Armitage, T. Berglundh et al., "A new classification scheme for periodontal and peri-implant diseases and conditions - Introduction and key changes from the 1999 classification," Journal of Periodontology, vol. 89, pp. S1-S8, 2018.

[28] J. G. Caton, G. Armitage, T. Berglundh et al., "A new classification scheme for periodontal and peri-implant diseases and conditions - Introduction and key changes from the 1999 classification," Journal of Clinical Periodontology, vol. 45, pp. S1S8, 2018.
[29] Z. S. Natto, M. Aladmawy, M. Alasqah, and A. Papas, "Factors contributing to tooth loss among the elderly: A cross sectional study," Singapore Dental Journal, vol. 35, pp. 17-22, 2014.

[30] H. J. Shiau and M. A. Reynolds, "Sex differences in destructive periodontal disease: exploring the biologic basis," Journal of Periodontology, vol. 81, no. 11, pp. 1505-1517, 2010.

[31] H. J. Shiau and M. A. Reynolds, "Sex differences in destructive periodontal disease: a systematic review," Journal of Periodontology, vol. 81, no. 10, pp. 1379-1389, 2010.

[32] J. Bergstrom, "Tobacco smoking and risk for periodontal disease," Journal of Clinical Periodontology, vol. 30, no. 2, pp. 107-113, 2003.

[33] L. Jansson and S. Lavstedt, "Influence of smoking on marginal bone loss and tooth loss - A prospective study over 20 years," Journal of Clinical Periodontology, vol. 29, no. 8, pp. 750-756, 2002.

[34] R. M. Palmer, R. F. Wilson, A. S. Hasan, and D. A. Scott, "Mechanisms of action of environmental factors - Tobacco smoking," Journal of Clinical Periodontology, vol. 32, no. 6, pp. 180-195, 2005.

[35] J. Bergström, "Periodontitis and Smoking: An Evidence-Based Appraisal," Journal of Evidence-Based Dental Practice, vol. 6, no. 1, pp. 33-41, 2006.

[36] M. S. Tonetti, G. Pini-Prato, and P. Cortellini, "Effect of cigarette smoking on periodontal healing following GTR in infrabony defects: A preliminary retrospective study," Journal of Clinical Periodontology, vol. 22, no. 3, pp. 229-234, 1995.

[37] S. G. Grossi, R. J. Genco, E. E. Machtei et al., "Assessment of risk for periodontal disease. II. Risk indicators for alveolar bone loss," Journal of Periodontology, vol. 66, no. 1, pp. 23-29, 1995.

[38] S. G. Grossi, J. J. Zambon, A. W. Ho et al., "Assessment of risk for periodontal disease. I. Risk indicators for attachment loss," Journal of Periodontology, vol. 65, no. 3, pp. 260-267, 1994.

[39] L. J. Emrich, M. Shlossman, and R. J. Genco, "Periodontal disease in non-insulin-dependent diabetes mellitus.," Journal of Periodontology, vol. 62, no. 2, pp. 123-131, 1991.

[40] R. Kolte, A. Kolte, and R. Kohad, "Quantitative estimation and correlation of serum albumin levels in clinically healthy subjects and chronic periodontitis patients," Journal of Indian Society of Periodontology, vol. 14, no. 4, p. 227, 2010.

[41] Y. Shimazaki, M. Kushiyama, M. Murakami, and Y. Yamashita, "Relationship between normal serum creatinine concentration and periodontal disease in japanese middle-aged males," Journal of Periodontology, vol. 84, no. 1, pp. 94-99, 2013. 


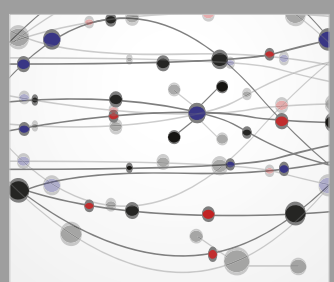

The Scientific World Journal
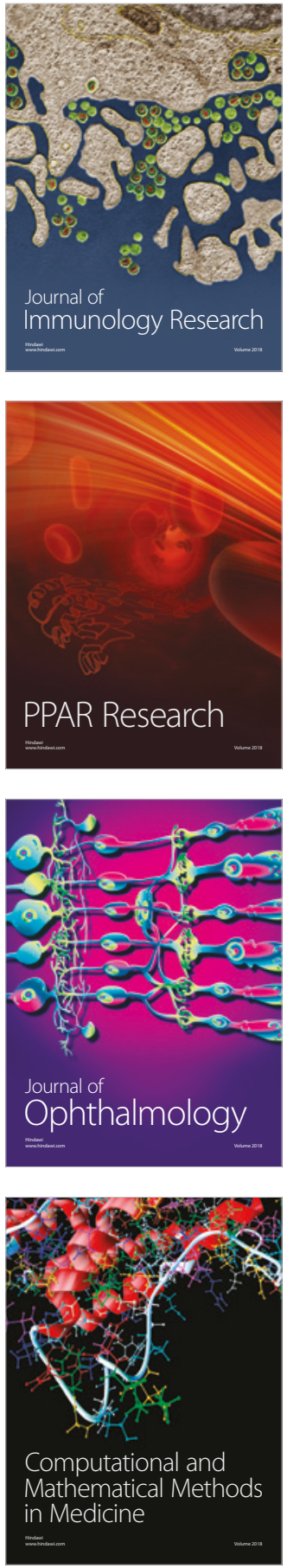

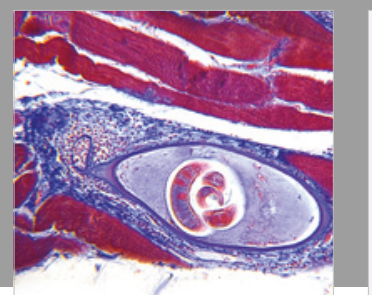

Gastroenterology Research and Practice

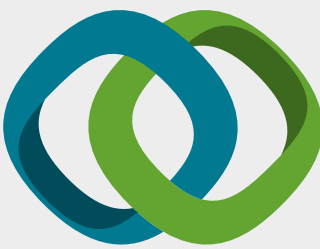

\section{Hindawi}

Submit your manuscripts at

www.hindawi.com
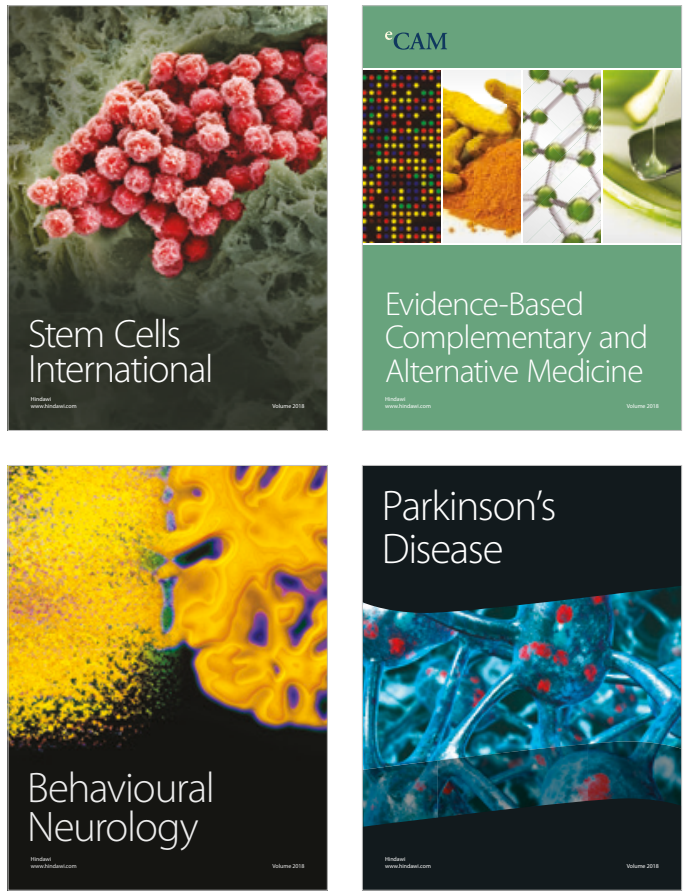

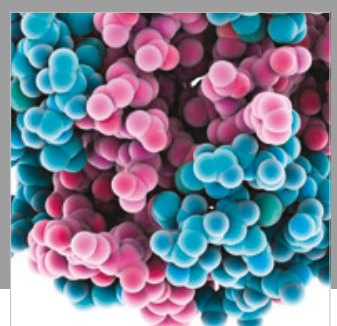

ournal of

Diabetes Research

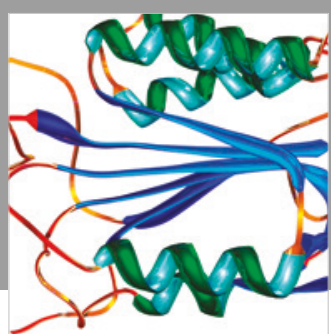

Disease Markers
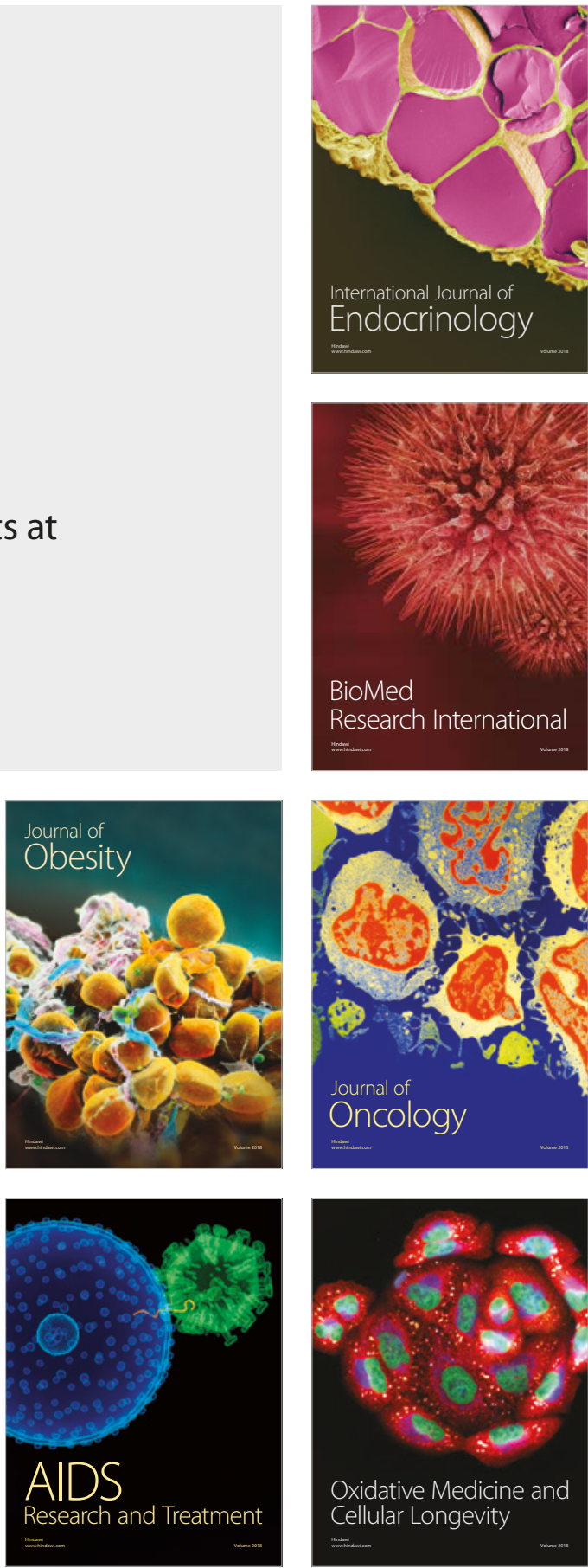